\title{
ИНСТИТУЦИОНАЛЬНОЕ СОВЕРШЕНСТВОВАНИЕ БЕЗОПАСНОСТИ В СИСТЕМЕ АДМИНИСТРАТИВНОГО ПРАВА
}

\begin{abstract}
Аннотация. Предметом исследования является безопасность как институт административного права, а также ее совершенствование. Автор подробно рассматривает институциональные особенности, которые необходимо учитывать при изменении законодательства и теоретических исследованиях. Особое внимание следует уделить концептуальным основам, в противном случае нормы о безопасности будут бесполезны для защиты общества, государства и личности.В статье уделено внимание проблеме смешения и подмены понятий, что мешает выстроить стройную систему безопасности, так как каждый раз требуются пояснения об объеме используемого понятия. Не оставлены без внимания и угрозы, трансформация которых также должна находить отражение в законодательстве и изменении методов и подходов к их устранению. Методологической основой исследования послужили как общенаучные методы: дедукция, индукция, анализ, синтез, - так и частно-научные методы исследования: историко-правовой,юридикодогматический, логический в сочетании с системным анализом исследуемых явлений, метод анализа нормативной базы. Изучен зарубежный опыт решения аналогичных вопросов. Основными выводами проведенного исследования явились: необходимость смены концепции безопасности, закладываемой в правовое регулирования; выстраивания системы безопасности, с определением понятийного аппарата и выделением таких правовых категорий, как правовое состояние (безопасность) и правоотношение (обеспечение безопасности); необходимость закрепления системных угроз в законодательстве и изменения подходов в реализации норм права.
\end{abstract}

Ключевые слова: административное право, институт административного права, национальная безопасность, государственное управление, изменение законодательства, анализ законодательства, концепция безопасности, угрозы безопасности, правовое регулирование, продовольственная безопасность.

Abstract. The research subject is safety as an institution of administrative law, and its improvement. The author examines institutional peculiarities, which should be taken into account in the process of changing the legislation and theoretical research. Special attention should be paid to the conceptual grounds, otherwise the safety norms will be useless for the protection of the society, the state and the person. The author pays attention to the problem of combination and substitution of terms, which hampers the creation of a harmonious safety system, since the term always needs to be explained. The article considers the threats, whose transformation should also be reflected in the legislation, and the change of methods of their elimination. The research methodology is based on general scientific methods (deduction, induction, analysis, synthesis) and specific methods (historical and legal, legal-dogmatic, logical, system analysis, and the method of analysis of normative provisions). The author studies the foreign experience in solving such problems. The author concludes that it is necessary to change the concept of safety, embedded in legal regulation; to create the safety system with the definition of the conceptual framework and such concepts as legal condition (safety) and legal relation (safety provision); to legislate the system threats, and to change the approaches to implementing legal regulations.

Key words: administrative law, administrative law institution, national safety, state management, change of legislation, analysis of legislation, concept of safety, security threats, legal regulation, food security, administrative law, institute of administrative law, national security, public administration, legislative change, analysis of legislation, security concept, security threat, legal regulation, food security.

3 аконодательство должно отражать систему общественных отношений, складывающихся на определенном этапе в государстве. Конец XX века характеризуется глобальными изменениями и усложнениями отдельных групп общественных институтов. Одним из таких институтов является безопасность.

Традиционно сложившиеся взгляды на безопасность, как военно-политические отношения, не соответствуют современному развитию. За по- следние тридцать лет общемировые концепции безопасности обогатились новыми, не военными и не политическими, типами угроз, делаются попытки преобразовать круг и статус участников, включая не только государства, но и надгосударственные структуры, региональные и местные власти, общественные организации, а также расширить круг мер, форм взаимодействия и подходов для ее обеспечения. Следует учитывать, что вопросами безопасности занимаются специалисты самых 


\section{Административное и муниципальное право 3 (99) • 2016}

разных направлений, от политики и экономики, до социологии. Остается определить: какую роль для данного института играет право.

Важнейшей единицей права является правоотношение. Оно рассматривается через наличие взаимных прав и обязанностей участников, юридических фактов и норм права. Но для института безопасности данный подход не позволяет выстроить комплексную систему, так как существует прямая необходимость в рамках правового регулирования ответить на ряд вопросов.

Во-первых, какая концепция безопасности является базовой для выстраивания законодательства. На сегодня сложились реалистическая (традиционная, положенная в основу законодательства еще в середине 60-х годов XX века), либеральная и социальная концепции. Различия концепций заключаются в составе субъектов, объектов, применяемых мер воздействия и др.

Во-вторых, сложность определения понятия безопасности. Для правового регулирования существует необходимость определиться с двумя правовыми категориями: рассмотреть безопасность как правовое состояние и определить особенности обеспечения безопасности как правоотношения.

В-третьих, от чего необходимо защитить объекты? Трансформация угроз требует отражения их в законодательстве, а также учета их особенностей в последующей реализации норм права.

В-четвертых, для реализации норм права следует определить юридические формулы, неправильное применение которых ведет к искажению правоотношений или отсутствию общественного результата.

Принятие в качестве базовой определенной концепции позволяет участникам правоотношений уяснить логику отношений. Основным законом на сегодняшний день является Федеральный закон от 28.12.2010 N 390-Ф3 «0 безопасности». Исследование действующего закона формально не дает возможности выявить базовую концепцию. То есть отсутствуют легально закрепленные субъекты, объекты безопасности, их правовые статусы, принципы правового регулирования и государственного управления безопасностью, интересы, которые должны защищаться и другие характеристики безопасности. Нет смысла углубляться в проблематику конкретного закона, так как детальный анализ можно найти в работах А.Н. Калюжного[1]. Фактически закон базируется на реалистической концепции, то есть субъектом и объектом признается государство, угрозы носят традиционный, то есть военно-политический характер. Это подтверждается, например, тем, что основным субъектом отношений закреплен Президент РФ, 1/3 закона посвящена Совету безопасности при Президенте РФ, который готовит решения по вопросам обеспечения безопасности, организации обороны, военного строительства, оборонного производства, военно-технического сотрудничества Российской Федерации с иностранными государствами, по иным вопросам, связанным с защитой конституционного строя, суверенитета, независимости и территориальной целостности Российской Федерации, а также по вопросам международного сотрудничества в области обеспечения безопасности (ст. 13).

Кроме того, существует, в определенном смысле, игра терминологией. Так, сложным является смысловое наполнение понятия «национальная безопасность» и его смешение с понятием «государственная безопасность». Существуют работы, где обосновывается необходимость рассмотрения под национальной безопасностью только государственной безопасности[2]. Такая беспечность в терминологии присутствует в Стратегии национальной безопасности до 2020 года, которая Федеральным законом «0 безопасности» определяется как исходный концептуальный документ. При этом сам по себе документ выстроен на той же реалистической теоретической концепции (на первом месте традиционно рассматривается оборона - прим. автора) с элементами (!!!) социальной. Элементами другой концепции является закрепление в качестве объектов безопасности личности, общества и государства, а также в качестве субъектов указаны институты гражданского общества, с которыми должно осуществляться взаимодействие. В тексте активно прослеживается непоследовательность в терминологии, игра местами объектов безопасности, введение в текст системных угроз, но решать проблемы предлагается несистемными мерами. Так, например, «в области повышения качества жизни российских граждан будут способствовать снижение уровня организованной преступности, коррупции и наркомании, противодействие преступным формированиям в легализации собственной экономической основы...».

Помимо проблемы смешения понятий «национальная безопасность» и «государственная безопасность», существует проблема определения «общественной безопасности». Само понятие общественной безопасности не имеет легального закрепления и, с советского периода, связано с защитой от противоправного посягательства и общественным порядком. То есть рассматриваемые угрозы носят несистемный характер. Детальный анализ Концепции общественной безопасности в Российской Федерации можно увидеть в работах А.В. Ростокинского[3].

Собственно говоря, все рассмотренные документы не позволяют определить понятие безопасности и ее систему. Под системой безопасности 
следует рассматривать совокупность взаимосвязанных уровней (международная; национальная, включающая общественную и государственную безопасность; личностная безопасность) и отраслевых (политическая, экономическая, социальная, экологическая) и межотраслевых (продовольственная, туристическая и др.) видов.

Институциональное развитие безопасности требует формирования общетеоретических правовых концепций, позволяющих рассматривать ее в разрезе правоотношений. Формулирование понятия «безопасность» через признак «состояние» позволяет рассматривать ее как статическую категорию. Здесь следует учесть, что как бы статично не было понятие «состояние», но характеристика дается обществу, находящемуся в постоянном движении и изменении. Попытка закрепить состояние общества на конкретном уровне в реальности приведет к стагнации и, в дальнейшем, к деградации. Поэтому термин «состояние общества» должен предполагать устойчивое развитие этого общества.

Применив общую теорию публичных правоотношений, предлагаемую Е.Б. Лупаревым, безопасность можно рассмотреть как правовое состояние, под которым понимаются «юридические факты, возникающие в результате реализации норм права вне правоотношений и в ряде случаев являющиеся обязательными предпосылками возникновения правоотношений»[4]. С точки зрения данного подхода безопасность представляет собой такую форму правового опосредования государственноуправленческой действительности, как правовое воздействие. Данная форма предполагает статическое, общерегламентационное, информационное влияние государства на управленческие общественные отношения в целях моделирования и установления общего правового режима и правового статуса субъектов, осуществляемое помимо и вне возникновения правоотношений. Однако, правовое воздействие не предполагает правоотношений. Результатом активной деятельности государства и его органов является правовое регулирование, для которого требуется определить формы и методы действий и, в том числе, воздействий, необходимых для поддержания статичного состояния. В научной и практической литературе для характеристики правового регулирования безопасности сложилось понятие обеспечения безопасности. Так, Н.Н. Терехова дает следующее определение: «Под обеспечением национальной безопасности в Российской Федерации понимается целенаправленная деятельность государственных и общественных институтов, а также граждан, по выявлению, предупреждению угроз безопасности личности, общества и государства и противодей- ствию им как обязательное и непременное условие защиты национальных интересов России»[5]. Воронов А.Н., употребляя понятие «организация обеспечения общественной безопасности», понимает под термином государственно-управленческую деятельность[6]. Таким образом, правоотношения будут возникать при обеспечении безопасности.

Третий проблемный вопрос связан с характеристикой угроз, от которых необходимо защитить объекты безопасности. Российское законодательство о безопасности построено на необходимости защиты от несистемных угроз, то есть разовые воздействия (война, конфликт, правонарушение), и не закрепляет системные угрозы, например, неэффективность государственного управления, социальное неравенство, деградация или отсутствие инфраструктуры и т.д. Собственно говоря, системные угрозы не вписываются в реалистическую концепцию безопасности. Последний закон принят в 2010 году, а концепция разработана в середине XX века, и это означает только одно: закон изначально устаревший и не отражает поменявшихся уже общественных реалий. В этом вопросе интересен опыт Китая, стратегия национальной безопасности которого характеризует традиционные (несистемные) и нетрадиционные (системные) угрозы и предлагает уделять повышенное внимание укреплению потенциала невоенного характера для ликвидации нетрадиционных угроз и вызовов[7].

Следует учитывать, что закрепление системных угроз потребует совсем иных правовых механизмов, в отличие от несистемных. Законодательство, ориентированное на систему запретов не может отреагировать на системные угрозы, так как, самих по себе юридических фактов, против которых должно быть направлено защитное мероприятие, не существует. Система государственного управления должна выстраиваться на профилактических/превентивных мероприятиях (например, системный мониторинг), а эффективность деятельности определяться через социальные интегральные показатели. И здесь возникают другая проблема: в чьи полномочия должна входить разработка системы угроз и социальных показателей, определяющих состояние объектов безопасности. Вряд ли целесообразно, например, предоставлять полномочия по определению показателей отчетности отчитывающемуся органу государственного управления. Самый главный навык, который наше общество, в том числе и органы государственного управления, приобрело за последние пол века - это умение отчитываться. Вот только для безопасности данный навык не решает ничего. Возможно, выходом для построения института безопасности был бы отказ от отчетности органами государственного управления и сбора определенных показателей 
независимыми структурами. Хотя, конечно, встает вопрос кто будет финансировать независимые структуры и определять их деятельность.

И последний вопрос связан с правильным применением норм о безопасности. Безопасность - институт публичного права, базовые аспекты которого закреплены в конституционном и административном праве. Нормы права реализуются в правоотношениях на основании юридической формулы «разрешено то, что разрешено». Для института безопасности это означает, что основной базой являются обязательные позитивные нормы. А правонарушения - это небольшая часть повседневных правоотношений. Активный уход законодателя в запреты приводит к тому, что не определяются правила должного поведения, либо они устаревают, либо просто не соответствуют складывающимся отношениям. Крайним негативным вариантом является перерегулирование безопасности, то есть формулирование такого объема норм, который невозможно реализовать: найти, прочитать, представить схему реализации и пошагово выполнять планомерно и систематически. В качестве примера можно привести зарегулированность пожарной безопасности. К тому же, в рамках реализации норм права участники не стимулируются государством на добровольное выполнение правил поведения о безопасности. Позитивное регулирование становится обузой, так как важно определить, кто виноват и, привлечь к ответственности.

Безопасность - важный социальный показатель, который приобрел на сегодня системные характеристики и усложнился. Реализация через законодательство затронутых вопросов позволит повысить степень защищенности всех объектов безопасности.

\section{Библиография:}

1. Калюжный А.Н. Федеральный закон "О безопасности": итоги реализации и перспективы развития // Военноюридический журнал. 2014. N 3. С. 7-10.

2. Вишнякова В.Г., Андриченко Л.В., Боголюбов С.А., Васильева Л.Н., Гравина А.А., Казанцев Н.М., Конюхова Т.В., Минина Е.Л., Трикоз Е.Н., Чертков А.Н. Национальная безопасность Российской Федерации: проблемы укрепления государственно-правовых основ // Журнал российского права. 2005. №2. С.3-34.

3. Ростокинский А.В. Неудобные вопросы авторам Концепции общественной безопасности в Российской Федерации // Российский следователь. 2014. N 6. С. 40-43.

4. Лупарев Е.Б. Общая теория публичных правоотношений: монография / Е. Б. Лупарев, М. Б. Добробаба, Т. В. Мокина. Москва, 2011.

5. Терехова Н.Н. Система обеспечения безопасности личности в общей структуре обеспечения национальной безопасности Российской Федерации // Вестник Удмуртского университета. 2012. №2-1. С. 144-150.

6. Воронов А.М. Общественная безопасность: административные и информационно-правовые проблемы обеспечения: автореф. дисс. ... докт. юрид. наук. М., 2005.

7. Диченко А.А. Изучение нетрадиционных аспектов безопасности в КНР // Международное публичное и частное право. 2014. N 4. С. 30-34.

8. Е. А. Белокрылова О некоторых юридико-технических проблемах обеспечения национальной безопасности в свете общих положений Федерального закона от 28 декабря 2010 г. №390-Ф3 «0 безопасности» // Национальная безопасность / nota bene. - 2011. - 5. - С. $34-44$.

\section{References (transliterated):}

1. Kalyuzhnyi A.N. Federal'nyi zakon "O bezopasnosti": itogi realizatsii i perspektivy razvitiya // Voenno-yuridicheskii zhurnal. 2014. N 3. S. 7-10.

2. Vishnyakova V.G., Andrichenko L.V., Bogolyubov S.A., Vasil'eva L.N., Gravina A.A., Kazantsev N.M., Konyukhova T.V., Minina E.L., Trikoz E.N., Chertkov A.N. Natsional'naya bezopasnost' Rossiiskoi Federatsii: problemy ukrepleniya gosudarstvennopravovykh osnov // Zhurnal rossiiskogo prava. 2005. №2. S.3-34.

3. Rostokinskii A.V. Neudobnye voprosy avtoram Kontseptsii obshchestvennoi bezopasnosti v Rossiiskoi Federatsii // Rossiiskii sledovatel'. 2014. N 6. S. 40-43.

4. Luparev E.B. Obshchaya teoriya publichnykh pravootnoshenii: monografiya / E. B. Luparev, M. B. Dobrobaba, T. V. Mokina. Moskva, 2011.

5. Terekhova N.N. Sistema obespecheniya bezopasnosti lichnosti v obshchei strukture obespecheniya natsional'noi bezopasnosti Rossiiskoi Federatsii // Vestnik Udmurtskogo universiteta. 2012. №2-1. S. 144-150.

6. Voronov A.M. Obshchestvennaya bezopasnost': administrativnye i informatsionno-pravovye problemy obespecheniya: avtoref. diss. ... dokt. yurid. nauk. M., 2005.

7. Dichenko A.A. Izuchenie netraditsionnykh aspektov bezopasnosti v KNR // Mezhdunarodnoe publichnoe i chastnoe pravo. 2014. N 4. S. 30-34.

8. E. A. Belokrylova 0 nekotorykh yuridiko-tekhnicheskikh problemakh obespecheniya natsional'noi bezopasnosti $\mathrm{v}$ svete obshchikh polozhenii Federal'nogo zakona ot 28 dekabrya 2010 g. №390-FZ «O bezopasnosti» // Natsional'naya bezopasnost' / nota bene. - 2011. - 5. - C. $34-44$. 